\title{
DYNAMICS OF CELL POPULATION STRUCTURE IN LIVER BIOPSY OF THE PATIENTS WITH CHRONIC HEPATITIS VIRAL INFECTION
}

\author{
IVAN I. TOKIN ${ }^{1}$, IVAN B. TOKIN ${ }^{2}$, GALINA FILIMONOVA ${ }^{2}$, \\ PIRET HUSSAR ${ }^{3}$ \\ ${ }^{1}$ St. Petersburg Medical Academy, Russia \\ ${ }^{2}$ St. Petersburg State University, Russia \\ ${ }^{3}$ Institute of Anatomy, University of Tartu, Estonia
}

\begin{abstract}
The cell population analysis of liver biopsies from the patients with both chronic hepatitis, chronic viral hepatitis $\mathrm{C}(\mathrm{HCV})$ and chronic viral hepatitis $\mathrm{B}$ (HBV) included the comparative evaluation of the specific part of nonparenchymal elements, analysis of the liver plates and sinusoids areas, the cell population of liver plates and sinusoids, the caryometric description of different types of cells. The essential difference of similar quantitative indexes in the biopsy specimens of patients with HCV and HBV was revealed and discussed. In total, the quantitative analysis of cell population structure in liver biopsies during the course of chronic hepatitis, especially in the case of defective biopsies, could be used for diagnostics and prognoses by expert evaluation.
\end{abstract}

Key words: liver biopsy, chronic viral hepatitis, morphometric analysis, caryometric analysis

\section{INTRODUCTION}

The histopathological study of the liver biopsy in viral hepatitis is very important for the determination of the severity, stage and prognosis of the disease $[1,2]$. Severity is graded according to the extent of necroinflammatory lesions; the staging of progression is based on the extent of fibrosis. At the same 
time the information about the cell population structure of liver biopsy of the patients with chronic viral hepatitis is very scarce. So, the nuclei size and the nuclei shape measurement have been applied in normal liver and hepatomas [3]. The diameter of nuclei and the cytoplasm of HBsAg-positive hepatocytes was also measured [4]. This study attempts to determine quantitatively whether hypertrophy, hyperplasia, and dysplasia are associated with HBVinfected hepatocytes. In our investigation the cell population analysis of liver biopsies from the patients with both chronic hepatitis, HCV and HBV included the evaluation of the specific part of non-parenchymal elements, the analysis of liver plates and sinusoids areas, the quantitative calculation of different types of cells in the composition of liver plates and sinusoids.

\section{MATERIAL AND METHODS}

\section{Patients}

Different groups of patients with chronic viral hepatitis $\mathrm{C}(\mathrm{HCV})$ and chronic viral hepatitis $\mathrm{B}(\mathrm{HBV})$ were investigated. $15 \mathrm{HCV}$ and $9 \mathrm{HBV}$ patients with mild, moderate and severe degree of fibrosis according to the classification by Ishak and METAVIR $[1,5]$ participated in the study. The diagnosis of chronic $\mathrm{HCV}$ and chronic HBV was established after the careful examination of patients: the anamneses of diseases and life, laboratory analyses, virological and morphological studies. To refine the diagnosis as well as for the detection of activity of pathological processes in the liver, aspiration biopsy according to $\mathrm{G}$. Menghini $[6,7]$ was taken from all the patients.

\section{Histological evaluation}

Samples of biopsies were formalin-fixed and paraffin-embedded. Serial paraffin sections were cut at $5 \mu \mathrm{m}$. Hematoxylin-eosin stain was used. Each biopsy for necroinflammatory activity and fibrosis was assessed by two hepatologists.

\section{Stereometric analysis}

The calculation was carried out using the standard graticule ( 400 squares) by microscope magnification 400x. In each field of vision a quantity of nonparencymal liver structures was calculated as a sum of portal areas, hepatic vessels and intralobular infiltrations. Other liver structures such as liver plates and sinusoids, were considered as parenchyma. The relationship between parenchymal and non-parenchymal elements was calculated in percentage. 


\section{Cell population analysis}

The number of lytic necroses of necroses of hepatocytes, binucleated hepatocytes and polymorphous hepatocytes with large nuclei was calculated in the composition of liver plates. The number of Kupffer cells and endotheliocytes was determined in the composition of sinusoids. Calculation was performed in the standard field of vision of microscope at the magnification $400 \times$ in the region of the middle zone of the liver lobule. Twenty standard fields of vision were investigated for each biopsy. Statistical analysis was performed by the tabulated processor Microsoft Excel 2003 and STATISTIKA 9.0. Pearson and Spearman correlation coefficients were used to evaluate the structure of population.

\section{Karyometric analysis}

The measurement of the nuclei square of the different types of cells in the composition of liver plates and sinusoids was performed. We also calculated the square of nuclei of mononucleated and binucleated hepatocytes, The Kupffer cells and endotheliocytes. All the measurements were realized by the special computer program of the microscope "Microvisor" (Russia).

\section{RESULTS}

\section{Cell population structure of liver biopsies from the patients with both chronic hepatitis, HCV and HBV}

Only sufficiently large biopsies with 5-6 portal zones can be suitable for the quantitative evaluation of the parenchymal elements of the liver by the methods of stereological or computer morphometry. Nevertheless, biopsies used to have frequently small sizes or consist of fine fragments without portal zones in clinical practice. The quantitative analysis of parenchyma elements (liver plates and sinusoids cells) is advisable in these cases.

In our investigation the cell population analysis of liver biopsies from the patients with both chronic hepatitis, $\mathrm{HCV}$ and $\mathrm{HBV}$ included the comparative evaluation of the specific part of non-parenchymal elements, the analysis of the liver plates and sinusoids areas, the cell population of liver plates and sinusoids. Comparative analysis of the specific part of non-parenchymal elements 
The specific part of non-parenchymal elements in the liver biopsies of patients with HCV (Table 1) strongly varies: from $2.16 \%$ to $11.93 \%$ (the mean value is $6.9 \pm 0.8 \%)$.

The piecemeal and bridging necroses are presented (Figure 1 and Figure 2 ), as a rule, in the liver biopsies of the patients with a high index of nonparenchymal elements. The piecemeal necroses are described in 11 cases from 15, bridging necroses in 7 cases from 15 . Such distribution shows that during the ordinary course of the disease the piecemeal necroses arise from the beginning, the bridging necroses are discovered later.

Table 1. Cell population structure of liver plates and sinusoids in the patients with HCV

\begin{tabular}{lcccccccc}
\hline $\begin{array}{c}\text { Biopsy } \\
\text { number }\end{array}$ & $\begin{array}{c}\text { Non- } \\
\text { paren- } \\
\text { chymal } \\
\text { ele- } \\
\text { ments, } \\
\%\end{array}$ & $\begin{array}{c}\text { Liver } \\
\text { plates, } \\
\%\end{array}$ & $\begin{array}{c}\text { Sinu- } \\
\text { soids, } \\
\%\end{array}$ & $\begin{array}{c}\text { Lytic } \\
\text { necroses } \\
\text { of hepa- } \\
\text { tocytes }\end{array}$ & $\begin{array}{c}\text { Binuc- } \\
\text { leated } \\
\text { hepa- } \\
\text { tocytes }\end{array}$ & $\begin{array}{c}\text { Polymorp } \\
\text { hous } \\
\text { hepa- } \\
\text { tocytes }\end{array}$ & $\begin{array}{c}\text { Endo- } \\
\text { thelio- } \\
\text { cytes }\end{array}$ & $\begin{array}{c}\text { Kupffer } \\
\text { cells }\end{array}$ \\
\hline 1 & 2.16 & 96.77 & 3.23 & 2.70 & 0.90 & 0.40 & 5.80 & 11.10 \\
\hline 2 & 2.46 & 92.68 & 7.32 & 1.60 & 2.40 & 0.90 & 7.30 & 6.90 \\
\hline 3 & 3.6 & 94.23 & 5.77 & 3.80 & 2.70 & 0.60 & 8.00 & 9.10 \\
\hline 4 & 4.3 & 95.10 & 4.90 & 3.50 & 1.00 & 1.30 & 7.20 & 5.30 \\
\hline 5 & 4.63 & 94.90 & 5.10 & 4.60 & 1.50 & 0.80 & 10.20 & 10.90 \\
\hline 6 & 4.7 & 93.74 & 6.26 & 2.80 & 0.30 & 0.00 & 8.90 & 6.90 \\
\hline 7 & 5.06 & 95.42 & 4.58 & 5.70 & 1.30 & 0.10 & 12.00 & 6.90 \\
\hline 9 & 5.18 & 93.32 & 6.68 & 2.60 & 0.30 & 0.10 & 7.60 & 10.70 \\
\hline 10 & 6.64 & 93.55 & 6.45 & 5.20 & 0.30 & 0.50 & 7.70 & 9.80 \\
\hline 11 & 9.46 & 94.68 & 5.32 & 4.40 & 1.70 & 0.80 & 12.80 & 15.80 \\
\hline 12 & 9.68 & 94.35 & 5.65 & 5.70 & 0.50 & 0.70 & 9.90 & 8.80 \\
\hline 13 & 10.56 & 92.16 & 7.84 & 4.60 & 1.10 & 0.90 & 11.30 & 12.00 \\
\hline 14 & 10.89 & 94.94 & 5.06 & 5.50 & 1.30 & 0.00 & 7.20 & 7.00 \\
\hline 15 & 11.76 & 93.00 & 7.00 & 3.80 & 2.70 & 1.90 & 9.70 & 14.00 \\
\hline & 11.93 & 92.87 & 7.13 & 3.10 & 0.90 & 0.60 & 10.40 & 9.20 \\
\hline
\end{tabular}




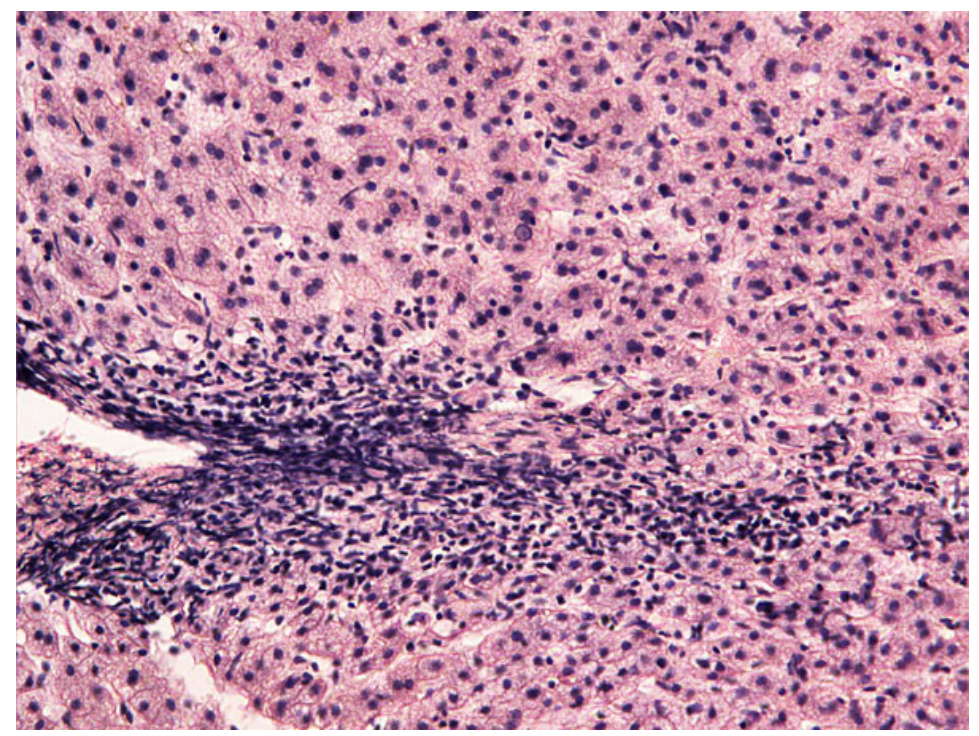

Figure 1. Fragment of portal tract with the damage of limiting plate and the development of piecemeal necroses in the liver of a patient with HBV. Hematoxylin-eosin. Obj.20x

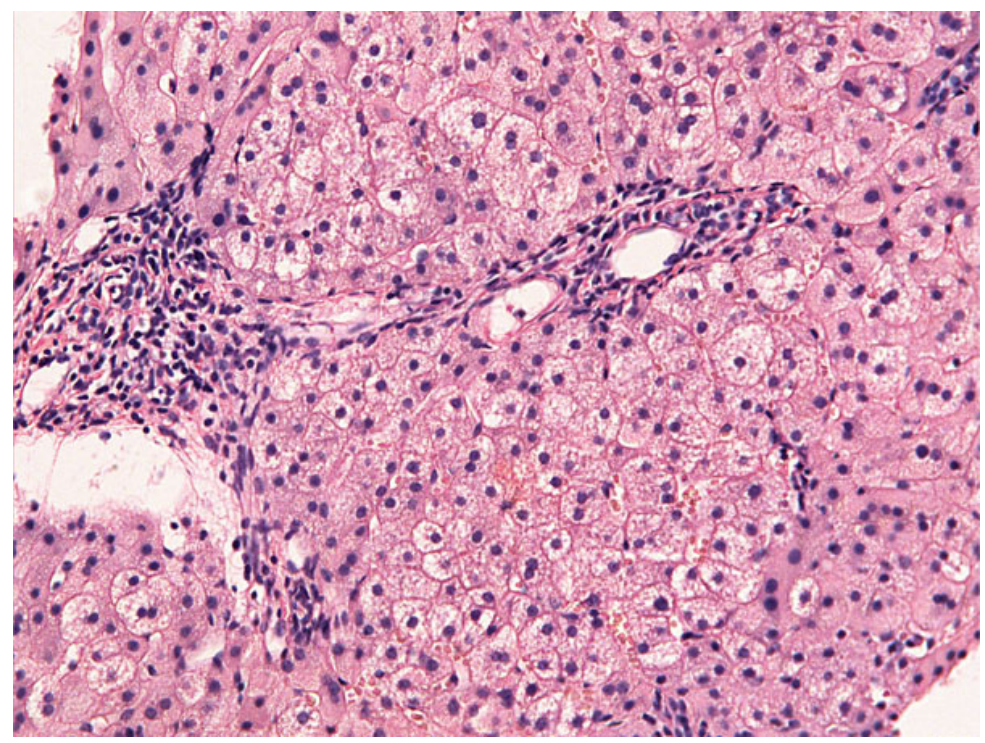

Figure 2. Fragment of portal tract with the damage of limiting plate and the development of bridging necroses in the liver of a patient with HCV. Hematoxylin-eosin. Obj.20x 
The specific part of non-parenchymal elements changes from $2.39 \%$ to $8.41 \%$ (the mean value is $3.8 \pm 0.9$ ) in the liver biopsies of the patients with HBV (Table 2). The piecemeal necroses were observed only in one biopsy, the bridging necroses in two biopsies.

The data regarding the specific parts of non-parenchymal elements shows that liver damages of the patients with HCV are more significant in comparison with the analogical indexes of patients with HBV.

\section{Analysis of the liver plates and sinusoids area}

Morphometric investigation shows that the specific parts of the liver plates of patients with HCV slightly vary from $92.16 \%$ to $96.77 \%$ (the mean value is $94.1 \pm 0.31$ ). The specific parts of sinusoids vary from $3.23 \%$ to $7.84 \%$ (the mean value is $5.9 \pm 0.4$ ). Such variations are more significant in the livers of the patients with HBV. The specific parts of liver plates in this case vary from $85.77 \%$ to $93.87 \%$ (the mean value is $90.98 \pm 0.32$ ), the specific parts of sinusoids vary from $6.13 \%$ to $14.23 \%$ (the mean value is $9.02 \pm 0.32$ ). Morphological and morphometric studies show (Figures 3 and 4; Tables 1 and 2) that the sinusoids of the liver biopsies of the patients with HCV significantly more narrowed than such of the patients with HBV. Respectively the conditions of intralobular blood circulation are significantly differ under various types of hepatitis.

Thus, the connection between the disease severity and the specific parts of liver plates and sinusoids are not established.

Table 2. Cell population structure of liver plates and sinusoids in patients with HBV

\begin{tabular}{lllllllll}
\hline $\begin{array}{l}\text { Biopsy } \\
\text { number }\end{array}$ & $\begin{array}{c}\text { Non-paren- } \\
\text { chymal ele- } \\
\text { ments, \% }\end{array}$ & $\begin{array}{c}\text { Liver } \\
\text { trabe- } \\
\text { cule, \% }\end{array}$ & $\begin{array}{c}\text { Sinu- } \\
\text { soids, } \\
\%\end{array}$ & $\begin{array}{c}\text { Dead } \\
\text { hepa- } \\
\text { tocytes }\end{array}$ & $\begin{array}{c}\text { Binuc- } \\
\text { leated } \\
\text { hepa- } \\
\text { tocytes }\end{array}$ & $\begin{array}{c}\text { Poly- } \\
\text { morp- } \\
\text { hous he- } \\
\text { patocytes }\end{array}$ & $\begin{array}{c}\text { Endo- } \\
\text { thelio- } \\
\text { cytes }\end{array}$ & $\begin{array}{c}\text { Kupfer } \\
\text { cells }\end{array}$ \\
\hline 1 & 2.39 & 91.65 & 8.35 & 6.75 & 1.00 & 1.00 & 6.25 & 7.15 \\
\hline 2 & 2.76 & 91.81 & 8.19 & 5.35 & 3.85 & 2.15 & 5.50 & 8.40 \\
\hline 3 & 2.78 & 93.29 & 6.71 & 2.05 & 1.80 & 1.15 & 8.05 & 8.45 \\
\hline 4 & 2.82 & 93.65 & 6.35 & 3.70 & 0.85 & 0.90 & 6.90 & 6.10 \\
\hline 5 & 2.86 & 85.77 & 14.23 & 1.30 & 4.10 & 2.35 & 7.35 & 6.15 \\
\hline 6 & 3.24 & 91.16 & 8.84 & 5.70 & 1.20 & 1.20 & 5.10 & 5.15 \\
\hline 7 & 4.32 & 93.87 & 6.13 & 4.91 & 1.36 & 0.91 & 8.64 & 5.73 \\
\hline 8 & 4.62 & 91.39 & 8.61 & 3.20 & 1.95 & 1.60 & 8.30 & 6.50 \\
\hline 9 & 8.41 & 86.26 & 13.74 & 3.55 & 4.90 & 1.70 & 8.45 & 8.40 \\
\hline
\end{tabular}




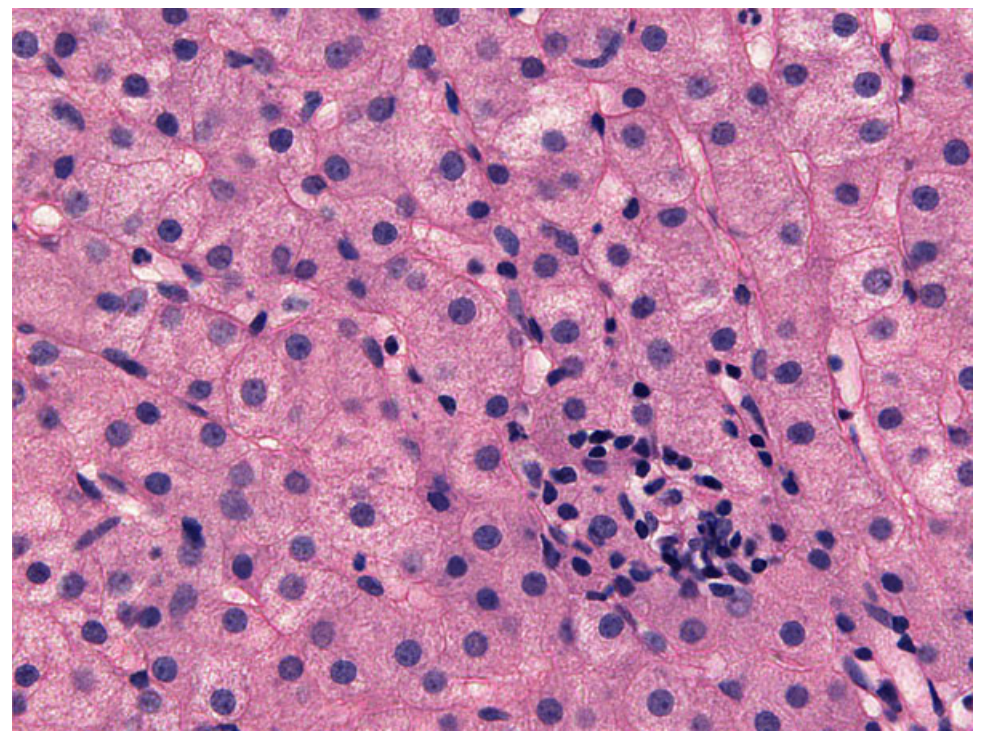

Figure 3. Fragment of parenchyma with intralobular necrosis, unimorphous hepatocytes and narrow sinusoids in the liver of a patient with HCV. Hematoxylin-eosin. Obj.40x

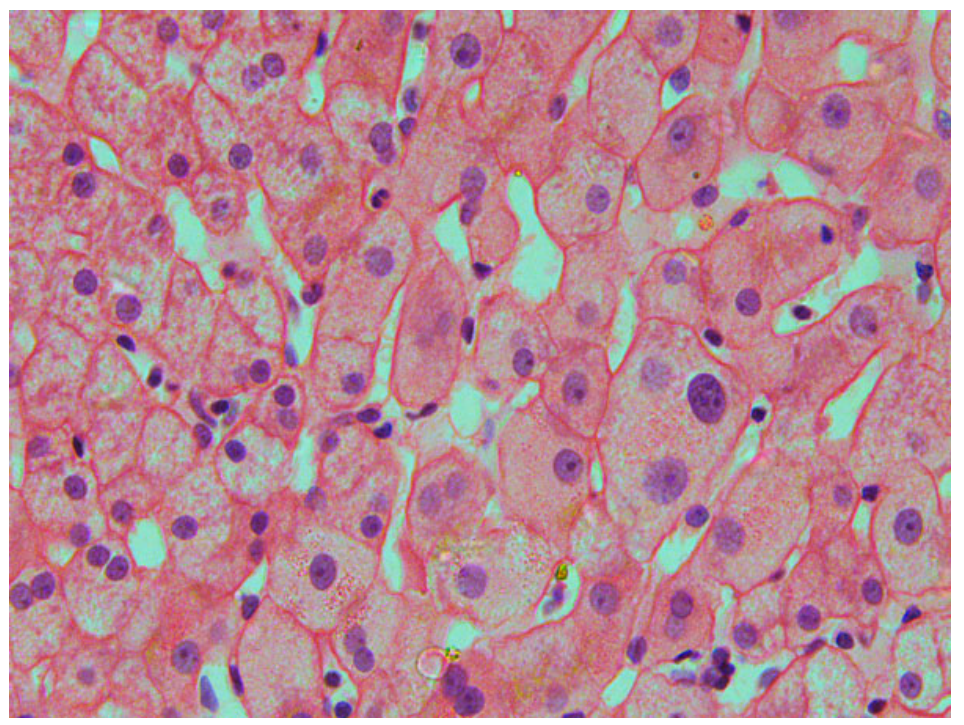

Figure 4. Fragment of parenchyma with polymorphous hepatocytes and distorted sinusoids in the liver of a patient with HBV. Hematoxylin-eosin. Obj.40x 


\section{Cell population of liver plates}

In the liver biopsies of the patients with chronic HCV (Table 1) the amount of lost hepatocytes (lytic necroses) in liver plates varies from $1.6 \%$ to $5.7 \%$ in the standard field of vision (the mean value is $3.97 \pm 04$ ). The number of binucleated hepatocytes varies from 0.3 to 2.7 (the mean value is $1.26 \pm 0.2$ ). The number of polymorphous hepatocytes in the standard field of vision varies from 0.0 to 1.9 (the mean value $0.64 \pm 0.1$ ).

In the liver biopsies of the patients with HBV (Table 2) the amount of lost cells varies from 1.3 to 6.75 (the mean value is $4.06 \pm 0.59$ ). The number of binucleated hepatocytes varies from 0.85 to 4.9 (the mean value is $2.33 \pm 0.5$ ). The number of polymorphous hepatocytes in the standard field of vision varies from 0.9 to 2.35 (the mean value is $1.44 \pm 0.3$ ).

Thus, the amount of single lytic necroses of hepatocytes does not differ in the liver biopsies of the patients with HBV and with HCV. At that time the number of binucleated hepatocytes and polymorphous hepatocytes is certainly higher in the liver biopsies of the patients with HBV. This situation may be connected with the different level of processes of regeneration.

\section{Cell population of liver sinusoids}

The amount of endotheliocytes in the sinusoids of the liver biopsies of the patients with HCV (Table 1) strongly varies: from 5.8 to 12.8 cells in the standard field of sight (the mean value is $9.0 \pm 0.5$ ). The amount of the Kupffer cells is also significantly differing from 5.3 to 15.8 in the field of sight (the mean value is 9.6 \pm 0.7 ). Nevertheless, the precise linear dependence between both of the indexes is not revealing.

The amount of endotheliocytes in the sinusoids of the liver biopsies of the patients with HBV (Table 2) weakly varies from 5.1 to 8.64 cells in the standard field of sight (the mean value is $7.17 \pm 0.13$ ). The amount of the Kupffer cells changes from 5.15 to 8.45 in the field of sight (the mean value is $6.89 \pm 0.31)$.

Thus, the amount of endotheliocytes and the Kupffer cells is essentially bigger in the liver biopsies of the patients with HCV. This circumstance is probably connected with the peculiarities of virus influence on the vessel component of liver parenchyma.

The cell population structure of the liver biopsies of the patients with HBV and HCV changes unequally. So, the use of the Student and the Satterwhite criteria allows discovering the statistically significant distinctions between the 
mean values of all the indexes with the exception of the amount of lost hepatocytes in liver plates.

The coefficients of correlation between the indexes of specific parts of liver plates and the number of binucleated cells, between the indexes of specific parts of liver plates and the number of polymorphous cells are statistically significant for the cluster of the liver biopsies of the patients with HBV.

The statistically significant coefficients of the Pearson correlation are not detected for the cluster of the liver biopsies of the patients with HCV.

The strong linear dependence between the indexes of the specific parts of liver plates and the number of binucleated cells and the number of polymorphous cells was revealed in the liver biopsies of the patients with HBV.

The use of the Spearmen coefficients of correlation allowed establishing the connection between the number of cells in sinusoids and the specific part of non-parenchymal elements in the liver biopsy of the patients with HBV. This circumstance could be used for indirect characteristics of the development of fibroses changes in liver.

In total, the quantitative analysis of the cell population structure in liver biopsies in the course of chronic hepatitis, especially in the case of defective biopsies, could be used for diagnostics and prognoses by expert evaluation.

\section{Karyometric analysis}

The Karyometric analysis was performed only in the liver biopsy from the patients with the mild degree of chronic HBV. Our investigation showed that the square of mononucleated hepatocytes strongly varied from $21 \mu \mathrm{m}^{2}$ to 76 $\mu \mathrm{m}^{2}$. Following mononucleated hepatocytes were distributed into 4 groups depending on the nuclei square. So, the $1^{\text {st }}$ group included hepatocytes with the nuclei square of $20-29 \mu \mathrm{m}^{2}, 2^{\text {nd }}$ group - with the square of nuclei $30-39 \mu \mathrm{m}^{2}$, $3^{\text {rd }}$ group - with the square of nuclei $40-49 \mu \mathrm{m}^{2}, 4^{\text {th }}$ group - with the square of nuclei more than $50 \mu \mathrm{m}^{2}$. In each group the number of mononucleated hepatocytes was $35 \%, 39 \%, 12 \%$ and $3 \%$ correspondingly. The nuclear square of binucleated hepatocytes varied from 47 to $78 \mu \mathrm{m}^{2}$. The nuclei square of the Kupffer cells and endotheliocytes changed similarly from 10 to $18 \mu^{2}$. In future we are planning to realize the caryometric investigation in the patients with the different degrees of both chronic HBV and chronic HCV activity. 


\section{DISCUSSION AND CONCLUSION}

In our investigation the morphometric analysis of the liver biopsies from the patients with both chronic hepatitis - HCV and HBV - included the comparative evaluation of the specific part of non-parenchymal elements, the analysis of the liver plates and the sinusoids areas, the cell population in the composition of liver plates and sinusoids, the karyometric analysis of hepatocytes, endotheliocytes and the Kupffer cells.

Non-parenchymal elements (portal zones with piecemeal and bridging necroses, intralobular infiltrates and occasional septa) are calculated by the stereometric analysis. The detailed morphometric analysis in liver biopsy specimens of the patients with chronic hepatitis $\mathrm{C}$ was presented. The comparative stereometric analysis of liver biopsy specimens from the patients with HCV and patients with HBV shows that liver damages of patients with $\mathrm{HCV}$ are more significant in comparison with the analogical indexes of the patients with $\mathrm{HBV}$.

The morphometric investigation of liver plates and the sinusoids areas shows that the sinusoids of the liver biopsies of the patients with HCV are significantly narrower than such of patients with HBV.

The analysis of the cell population of liver plates demonstrates that the number of binucleated and polymorphous hepatocytes is certainly higher in the liver biopsies of the patients with HBV. The amount of endotheliocytes and the Kupffer cells is essentially bigger in the liver biopsies of the patients with $\mathrm{HCV}$.

The caryometric analysis is important in the assessment of neoplasia, because the development of hepatocellular carcinoma is related to infection with the hepatitis B virus.

The quantitative analysis of the cell population structure in liver biopsies in the course of chronic hepatitis, especially in the case of defective biopsies, could be used for diagnostic and prognoses by expert evaluation.

\section{REFERENCES}

1. Ishak K., Baptista A., Bianchi L. et al. (1995). Histological Grading and Staging of Chronic Hepatitis. Journal of Hepatology, 22, 6, 696-699.

2. Brunt E. (2000). Grading and Staging the Histopathological Lesions of Chronic Hepatitis: The Knodell Histology Activity Index and Beyond. Hepatology, 31, 1, 241-246. 
3. Jagoe R., Sowter C., Dandy S. et al. (1982). Morphometric study of liver cell nuclei in hepatomas using an interactive computer technique: nuclear size and shape. J Clinical Pathol, 35, 1057-1062.

4. Chen V.L., Gerber M., Thung W. et al. (1984). Morphometric study of hepatocytes containing hepatitis B surface antigen. Am J Pathol, 114, 217-221.

5. French METAVIR Cooperative Study Group (1994). Intraobserver and Interobserver Variations in Liver Biopsy Interpretation in Patients with Chronic Hepatitis C. Hepatology, 20, 1 (July 1994), 15-20.

6. Menghini G. (1958). One-second Needle Biopsy of the Liver. Gastroenterology, 35, 2, 190-199.

Address for correspondence:

Piret Hussar, M.D., D.M.Sc

Institute of Anatomy

Faculty of Medicine

University of Tartu

Ravila 19, 50411 Tartu, Estonia

E-mail: piret.hussar@ut.ee 